Letros, Lima 48 (88-89); 7-20, 1985.

\title{
La Iglesia de Santo Domingo de Lima durante el siglo XVII
}

MARTHA I. BARRIGA TELLO

Entre fines del siglo XVI y principios del siglo XVII llegaron a Lima artífices españoles conocedores de la actividad constructora en las Ordenes monásticas europeas, a las que muchos pertenecían. Se debió en parte a la experiencia de estos artífices o a sus discípulos, la trasmisión de la corriente renacentista y la configuración que tomó la ciudad en el siglo XVII, considerado por muchos historiadores como el de mayor florecimiento en el Virreinato.

Terminado casi totalmente el templo dominico, los padres se dedicaron al embellecimiento de sus dependencias. Parte de esta labor fue la construcción de la fachada lateral del templo. Harold Wethey considera que fue encargada aproximadamente en la misma época que la de la Capilla de la Veracruz hecha por Diego Guillén en 1613, atendiendo a su similitud estilística con ésta. Ambas presentaban características herrerianas comparables con la fachada de Nuestra Señora de las Angustias de Valladolid hecha por Juan de Nantes entre 1597 y 1606: dos pisos con colummas clásicas corintias y entablamento corrido (1).

La fachada lateral que aparece en el grabado de la crónica de Juan Meléndez presenta dos cuerpos. El primero, de mayor dimensión, consta de un arco de medio punto flanqueado por columnas corintias dobles sobre basamentos. En los intercolumnios se aprecia hornacinas con esculturas. : En las enjutas del arco existen relieves. Separa el primero del segundo cuerpo un entablamento corrido. En el segundo cuerpo las columinas forman anchas calles entre las que también se ve hornacinas con esculturas.' En el nicho central en forma de arco de medio punto hay una escultura. Remata la fachada un frontón triangular cerrado en el que se aprecia una forma ovoidal con re-

$\therefore$ (1) WETHEY, Horold. Coloniol architecture and sculpture in Peru. (Combridge, Mass. 1949), 80. WOERMANN, Kärl. Historia del Arte. (Barcelona, 1959), T. V, 95. 
lieves. Completa el conjunto seis pináculos piramidales (2): Es muy similar por tanto a la de Nantes, que sobre las columnas corintias presenta un entablamento corrido en el primer cuerpo y un frontón triangular remata el segundo.

\section{La Construcción de la Primera Torre}

Años después, en 16.59, Fr. Martín Meléndez encargó una obra para la iglesia y fue la erección de una torre donde por entonces existía solamente una espadaña "que aunque era una hermosa fábrica estaba rajada por los temblores y amenazaba ruina, y en su lugar labró, desde los cimientos, una bellísima torre de tres cuerpos que es la única maravilla por su altura, por su arte, por su fortaleza de todo aquel nuevo Mundo" afirma el P. Meléndez (3). Dicha construcción pudo implicar.alguna variación en la cubierta, como lo menciona Mugaburu (4), aunque el cronista dominico no lo indica.

El trabajo de la torre lo llevaron a cabo Fr. Diego Maroto en el proyecto y Francisco Cano Melgarejo en la ejecución. Desde 1659 Maroto se hizo cargo de la mayor parte de las reformas que emprenđió la Orden. Para construir la torre fue necesario romper los muros que separaban la capilla de los Negros, la última del lado de la Epístola, del Coro Bajo. La torre, según la descripción que años después hizo el P. Meléndez, medía 14 varas castellanas de diámetro ( $11 \mathrm{mts}$. aprox.). Era ochavada, separada por tramos con cornisas, que disminuían de tamaño en orden ascendente. El primer cuerpo medía 17 varas castellanas ( $13 \mathrm{mts}$. aprox.) de alto, el segundo 15 varas $\left(11 \frac{1 / 2}{2}\right.$ mts. aprox.) y el tercero, donde iban las campanas, medía incluyendo el remate, 12 varas ( $9 \mathrm{mts}$-aprox.) ] Prosigue el cronista: "Aquí ejecutó el artífice un raro acierto, cuanto de ornato y primor supo concebir la idea, vense volar las cornisas, 90 quellas"sufre su peso, rasgarle diez y seis ventanas sin peligrar los macizos. Suspenderle los frontispicios y no dejarse tirar de su misma pesadumbre, irse a caer, las repisas, y asirse de las paredes, asomarse los recuadros sólo para que los vean amagar $\mathrm{y}$ arrojarse los motilos y quedarse todo su arrojo en amagos, arrimarse las pilastras de orden dórico, sin sentir el peligro de caerse, allí se dilatan los frisos y corren sin parar los arquitrabes, porque no hacen más que dar vueltas, allí diferentes cóncavos señalan

(2) Véase el grabado de Meléndez en WETHEY, H., Op. cit., ilustr. 102. Sobre la iglesia de Nantes: WOERMANN, K., Op. cit., 95.

(3) MELENDEZ, O. P., Juan. Tesoros verdaderos de Indias en la historia de la gran Provincia de San Juan Bautista del Perú ( 1681 ). (Roma, MDCLXXXI), T. III, Lib. V, Cap. XII, 786. El Campanario lo habia construido el maestro Antonio Mayordomo en 1632, conforme al modelo trazado por Juan García. (En: HARTH-TERRE, Emilio. La torre de Santo Domingo. Expreso, Lima, 17. XI-1976). Archivo particular Harth-Terre, A.N.P. Juan Valenzuela (Notario), Fol. 175).

(4) MUGABURU, Josephe de y Mugaburu, Francisco de. Diario de Lima (1640-1694), Lima, 1935. 75; HARTH-TERRE, Emilio, Una capilla muy galana. (El Comercio, Lima, 2-VI-1948). 
otras ventanas, mas no las rompen, que resistiéndole la fortaleza de la torre, aconsejada del arte, sólo las permitió que abrieran nichos. Sobre la última cornisa se levanta un sotabanco de cuatro varas de a!tura que coronan una cornisa de menos vuelo, y en él asentar la cúpula de media natanja, en cuyo convexo se abren cuatro guardas o balconcillos, y de alto abajo entre las guardas se requestan ocho cartelas en forma de arbotantes, por lo que pueden perder a la vista en la distancia: éstas reciben la escoria que también es ochavada, y sobre ella en la linterna con' su media naranjilla sirve de trono o peana a una estatua de la $\mathrm{Fe}$ de cuatro varas de alto con sus comunes insignias de Tiara, Cruz y Cáliz: porque aun así figurada se eleve su verdad hasta los cielos. Sobre los cuatro ángulos menores queda una mayor capacidad desde los vivos del macizo, hasta la superficie del círcúlo de la cúpula, y ésta la ocupan cuatro medias naranjillas con su ornato de linternas, y remates cada una con sus cuatro pilastras pequeñas que abrazan otros tantos arcos con sus recuadros y frontis, que a un tiempo dan sombra a cuatro balcones volados, que se atan con la baranda, que da vuelta a todo el banco por la última cornisa, y escoltan con valentía toda la máquina de la hermosa cúpula. Esta y el banco sobre el que estriba ocupan el aire diez y ocho varas de alto [14 mts.] sin las cuatro de la $\mathrm{Fe}$ [ $4 \mathrm{mts}$.], que con ellas y las cuatro que levantan los tres cuerpos, suman sesenta y seis varas [58 mts. aprox.]" (5).

De acuerdo con el arquitecto Harth-terré, las grandes almohadillas con que se adornó los paramentos de la torre, ya habían sido empleadas en los de La Merced y de San Agustín. En la iglesia de San Francisco este mismo detalle se transformó en cintas que doblaban las esquinas formando un nuevo tipo de almohadillado (6). Enrique Marco Dorta, asegura por su parte, que los arcos de descarga del primer piso de la torre eran práctica frecuente en las construcciones de la época (7).

En 1629 el P. Bernabé Cobo (8) describió la iglesia dominica como "muy grande y de costosa fábrica; de una nave con dos órdenes de capillas a los lados; éstas son de bóvedas curiosamente labradas y la nave del medio cubierta de madera y lacería curiosa; la capilla mayor es de bóveda y para tan grande iglesia es tenida por pequeña". Se-

(5) ,MELENDEZ, J., Op. cit,, T. I, Lib. I, Cop. VIII, 59.

(6) HARTH-TERRE, E., prólogo a GENTO SANZ, O.F.M., Benjamin, Saṇ Frenciseo de Limo. Limo, 1945. XIV.

(7) MARCO DORTA, Enrique. Historia del arte hispanoamericano. Barcelono, 1945. T. III, 333.

(8) $\mathrm{COBO}$ S. J. Bernabé. Historia de la fundación de Lima. Modrid, 1956, Lib. III, Cap. III, 418. Aquil Cobo menciono que lo iglesio era "grande". Un posible concierto para "alorgór el coro en los pies de la liglesio hasto el pretil del cementerio", (Antonio San Cristóbol, El Comercio, Lima, 2 de dic. 1982) no se justificaría. Añ́ádase a ello el controto paro el campanario (noto 3 supra) que debe conciliarse con lo modificoción de la plantó. 
gún el Diario de Mugaburu (9) en 1660 y 1666 la techumbre había sido derribada para construir una bóveda de cal y caña. El P. Meléndez, que escribió en 1681, describe la cubierta del templo en similares términos a los del P. Cobo, es decir, construida la techumbre de lacería dorada. Si en algún momento la bóveda que menciona Mugaburu se llegó a construir, debió de corresponder a otra sección, pues aun la cubierta del Coro era de lacería (10). En el caso que nos ocupa, pudo tratarse de alguna de las bóvedas de las naves laterales, varias de las cuales ya se habían realizado por esta época a base de cal y caña (11).

Cuando fue nombrado Vicario General y Visitador del Convento Fr. Martín Meléndez (1660-1662) su primera obra fue la construcción en la iglesia de una bodega grande para enterrar a los muertos, con lo que se evitó el tener que abrir sepulturas "con que era forzoso al cubrirlas padecer desigualdades del suelo" según anota el P. Meléndez (12).

\section{El Terremoto de 1678 y la Tercera Planta}

El 17 de junio de 1678 Lima soportó uno de los mayores sismos de su historia. Los daños que ocasionó en la iglesia dominica motivaron varias reparaciones y modifícaciones, llevadas a cabo por el entonces Provincial Fr. Juan de los Ríos (1677-1682) con la colaboración del Prior del convento Fr. Diego Maroto (1681-1684). Entre las obras más importantes que se deben al P. de los Ríos, está el haberle encargado a Fr. Juan Meléndez una historia de la Orden Dominica, de su convento, iglesia y santos principales (13).

El terremoto habia dañado la capilla mayor de la iglesia, por lo que fue preciso derribarla, pya que meses después, del sismo comenzaron a caer pedazos de estuco y material que amenazaban destruir el altar mayor (14).

Esta modificación si bien no implicó alterar las bóvedas de los tramos cercanos a la entrada, donde se mantuvieron las de nervadura gótica originales del siglo XVI (15), obligó a reedificar las capillas laterales a la capilla mayor y las de las naves laterales que forma-

(9) MUGABURU, J., Op. cit., 75. En un artículo (EI Comercio, Lima, 2 de dic. 1982) Antonio Son Cristóbal menciona un concierto entre Diego de la Gamo y Diego Maroto, por el que aquél se comprometió a levantar dos bóvedas de crucería de cal y ladrillo sobre el prebisterio de la iglesia dominica. No consigna fuente.

(10) MELENDEZ, J., Op. cit., T. I, Lib. I, Cap. VIII, 53.

(11) BUSCHIAZZO, Morio. Historia de la arquitectura colonial Ibero-

americana. Buenos Aires, 1961. 80.

(12) MELENDEZ, J. Op. cit., T. III, Lib. V, Cap. XII, 786.

(13) ANGULO, O. P., Domingo. Lo Orden de Santo Domingo en el Perú. Lima, 1908. 214.

(14) Ibidem, 215; MELENDEZ, J. Op. cit., T. III, Lib. V, Cap. IV, 810.

(15) BUSCHIAZZO, M., Op. cit., 80. 
bàn el crucero. Esta vez se reemplazó el material empleado hasta entonces en las bóvedas - ladrillo y piedra - por una armazón de madera y caña que al revestirse de estuco no presentaban diferencia con materiales más sólidos. En las bóvedas se simulaba luego en madera, las nervaduras de las góticas, procedimiento que ya había sido utilizado anteriormente en edificaciones religiosas limeñas (16).

. La iglesia, por la descripción del P. Meléndez en 1681 (17), medía 84 varas de largo ( $65 \mathrm{mts}$. aprox.), 36 de ancho $(29 \mathrm{mts}$ ) y 18 de alto (14 mits. aprox.). Se dividía en tres naves, la central medía 15 varas de ancho (12 mts. aprox.) y estaba formada de tres partes: la Capilla Mayor, el cuerpo de la iglesia y el Coro. La Capilla Mayor comprendía: a) El Presbiterio, que se situaba sobre cinco gradas de mármol y que tenía el ancho de la nave central. Se extendía 11 varas a lo largo ( 8.50 mts. aprox.); b) el Crucero y c) Dos capillas laterales.

Del Presbiterio por el lado del Evangelio se descendía al altar de Santo Domingo que estaba colocado sobre un grueso pilar colindante con el Coro: "y al otro lado se ve en la misma proporción el de nuestro angelino Doctor Santo Tomás de Aquino. Son de mediana estatura los Retablos, que se forman de dos cuerpos, pero en el aire, en lo dorado, y en la fábrica no deben nada al mayor. Después le sigue dos capillas que llaman de los Agüeros y Aliagas, la primera del Evangelio, y la segunda de la Épístola, aquella del Santo Cristo, enfrente de cuyo altar está colocado otro del famoso valenciano San 'Vicente Ferrer, y ésta de San Gerónimo, fundaciones tan antiguas, que comenzaron con la misma iglesia y labraron y dotaron a su costa, y de sus bienes los capitanes Diego de Agüero y Jerónimo de Aliaga de los primeros conquistadores del Reyno, yal pobladores de Lima, que hoy gozan sus herederos. Estas capillas, el Presbiterio, el Crucero están cubiertas de bóvedas, y las bóvedas vestidas de hermosísimas pinturas de célebres Paraninfos, que con decir, que el pincel, que las formó fue de la inano de Alezio, está ponderado todo cuanto se puede decir de su dibujo, su garbo, su colorido, su precio.

Lo restante de la Nave Principal hasta encontrar con el Coro, corre sobre cinco arcos vestidos de Profetas, y Sybilas, Virtudes y Santas Vírgenes del mismo famoso Alezio, cubiertas de lazería (18), con los perfiles dorados, que hacen una agradable vista, y entre arco y arco se yen rasgadas doce grandes ventanas, seis por banda, guarnecidas de arbotantes, y frontispicios dorados que descansan el espacio las tribunas, también doradas, cuyas repisas coronan los arcos de las capi-

(16) Loc. cit., y BAYON, Domión. Sociedod y arquitivetura colonial Sudomeritena. Borcelono, 1974, i09 ss.

(i7) MELENDEZ, J., Op. cit., T. I, Lib. I, Cap. VIII. Se ho convertido lo voro costellano a rozón de $772 \mathrm{~mm}$. 'Dice.' Real Acodamio de lo Lenguo), completándose la cantidad cuondo hobia frocción.

(18) Loc. cit., 57. Bernoles Ballesteros en Limo, b eluded y sue menumentos, Sevilla, 1972) afirmo que dice "crucerio" cuondo claramente se lee "Lazería", lo que concuerda con la descripción general de la iglesia que hace el cronista dominico (Bernales, Op. cit., 248). 
llas, por donde se comunican las dos naves de los lados con la nave principal; y en las gigantescas pilastras en que descansa la máquina de la iglesia hay siete hermosos retablos de muy gracioso ensamblaje; por el lado del Evangelio está frontero del púlpito el altar de Nuestra Señora de la Candelaria; a cuyos sagrados pies se miran hoy colocadas la Imagen y las Reliquias de nuestra hermosa paisana, y amantísima patrona, y de toda América, Santa Rosa de Santa María, mientras se les hace altar (que ya se está fabricando); luego el de San Pedro Martir, el de Santa María Magdalena y el de Santa Ludovina, que miran, al de la Epístola, al de Santa Catalina Virgen y Mártir, el de Santa Bárbara, y al de San Antonio Arzobispo de Florencia, y todos los retablos tienen en nichos menores repartidos los santos de la Orden de primorosa escultura.

La nave del Evangelio da principio con el altar, y Retablo de San Juan Bautista Patrón y Protector de la provincia, y en su capilla fundación del capitán Juan Fernández nuestro insigne bien hechor: luego le sigue el altar de Nuestra Señora Santa Ana, y tras él junto a la puerta, que sale de la Iglesia al Cimenterio [sic] el de la Seráfica Virgen Santa Catalina de Sena, cuyo nicho principal ocupa decentemente la devotísima imagen de Jesús Nazareno llevando la cruz a cuestas y a estos altares les corresponden al frente al lado de la Epístola, el primero el rico altar de Nuestra Señora del Rosario, imagen la más antigua, que ha conocido el Perú, [...]. Luego está el de las Reliquias que son innumerables, tesoro de más riqueza, que la que da Potosí, después el del nombre Santísimo de Jesús. T'Tas éste el del milagroso polaco San Jacinto, y haciendo frente al altar de Nuestra Señora del Rosario, y debajo del Coro en dos capaces capillas están otros tres altares de la misma advocación del Rosario, que sirven Indios, Morenos y Pardos, con pompas ys ostentación, nada inferior a los blancos, cuyos retablos dorados son embelezos del arte y la riqueza".

La escultura que menciona Meléndez de San Jacinto, fue realizada por uno de los primeros escultores limeños, Alonso Bautista de Guevara en 1596.

Prosiguiendo con su descripción del templo, el P. Meléndez detalla la apariencia del Coro. "Al Coro llamé gran pieza, y es corta ponderación, porque sin agravio de otro, es el mejor, con haberlos prodigiosos, que tiene todo el Perú; su latitud es igual a la nave primera de la iglesia, y su longitud se extiende por treinta varas cabales. Sobre la reja o baranda, por donde mira a la iglesia tiene una devotísima imagen del Señor puesto en la cruz dentro de un curioso Tabernáculo dorado, y por decencia cubierto con cristales vidrieras [...]. I.a sillería es de cedro, y el Fascistol de lo mismo de primoroso ensamblaje. De aquellas por cada banda del Coro, unas altas y otras bajas, fuera de unas bancas largas sin espaldar, que llamamos aca formas, hay cincuenta y nueve sillas, coronadas las superiores, de los espaldares arriba, de santos de media talla entre columnas vestidas de relieve, sobre 
quienes descansa una cornisa socabada a manera de docel,y encima los frontispicios que corresponden al número de sillas, entre galanos piríimides, y remates; obra de especial primor. El pavimiento es de alfombras de muy finos azulejos, y la techumbre de lacería dorada, la que llaman los de arte de cuenta del veinte y diez, que pasma la admiración. Súbese al Coro por una bella escalera de piedra cubierta costosamente de una bóveda de varios lazos y tarjas con los perfiles dorados, y a cuyo andar va subiendo arriba las paredes, una faja de finos azulejos de casi dos varas de ancho, que realza lo hermoso de su fábrica y da entrada a una gran sala, vestidas las paredes de azulejos, y hermosísimos cuadros de pintura, por donde se pasa al Coro, en cuya correspondencia, al otro lado, se cogen al Coro en medio, está otra Sala del tamaño de la primera, que sirve de librería, en que se guardan los libros Corales". (19)

Esta excelente descripción sintetiza las informaciones que hasta ahora se han proporcionado referidas a la fábrica y al adorno de la iglesia en sus retablos.y azulcjos.

\section{LA OBRA DE FR. DIEGO MAROTO}

En su afán de darle unidad a la construcción, Fr. Juan de los Ríos (1677-1682) emprendió la reforma de toda la nave central del templo dominico, desde el crucero hasta la testera del Coro. Se renovaron los arcos y rasgó cl ventanaje, dándole a la obra una apariencia sencilla y sobria. Luego mandó construir la portada principal de la iglesia, la lateral ya existía desde principios del XVII. La iglesia, como todas las de la ćpoca, tenía un cementerio hacia la calle, el mismo que el P. de los Ríos mandó cercar. Completó el adorno de la torre con tribunas, corredores lyccampháas. Fstas obras reportaron un gasto fuerte al convento, pucs solamente en la campana se invirtió 7.000 pesos (20).

El P. de los Ríos encargó estos trabajos de renovación al religioso dominico Fr. Diego Maroto. Maroto había nacido en Lima. Cuando se hizo cargo de los trabajos en la iglesia de Santo Domingo, ya tenía experiencia de varios años en el oficio de construcción. Su primer trabajo documentado data de 1643 , cuando intervino en las obras de la Catedral de Trujillo, cuyos planos le fucron encargados. Posteriormente, trabajó en las obras de refacción de la Catedral de Lima reemplazando a Pedro Noguera en 1656, el mismo año el Cabildo lo nombró Maestro Mayor de Reales Fábricas. En 1659 hizo la torre

(19) MELENDEZ, J., Op. cit., T. I, Lib. I, Cap. VIII, 53-57.

(20) ANGULO, O. P. D., Óp. cit., 215.' La primera campana colocada en la torre lo fue el 24 de abril de 1675, siendo Provincial Fr. Antonio de Morales. La campana mayor se puso el 19 de agosto de 1681 . Pesaba 220 quintales; MUGABURU, J., Op. cit., 182 y 215. 
de la iglesia de Santo Domingo, la misma que se aprecia en el grabado de Meléndez (21).

Con su experiencia en arquitectura, el P. Diego Moroto inició los trabajos de ampliación del crucero en 1681, de acuerdo a la nueva dimensión proyectada para la capilla mayor. Como era adenís Prior del convento, suscribió un acuerdo con los mayorazgos de Agüiero y de Aliaga, así como con la Cofradía de Nuestra Señora del Rosario para las reformas que resultasen en la modificación. Los Mayorazgos y cofrades otorgaron la aceptación por escrituras del 7 de setiembre de 1683 y del 30 de abril de 1684, ambas firmadas ante el Escribano Pedro Landero. El acuerdo implicaba la apertura de los muros que cerraban las capillas de Santo Cristo o de Agüero y la de San Jerónimo o de Aliaga. De esta manera quedaba conformado el crucero y modificada la segunda traza de la iglesia (22). El crucero así determinado se cubrió con una cúpula recubierta de estuco, construida por Fr. Diego Matoto entre 1681 y 1685 (23).

Ja cúpula que se construyó sobre el crucern descansaba sobre cuatro arcos torales. Era de pechinas con tambor octogonal, Remataba en un cupulino también octogonal. Al interior estaba revestido de estuco y con medias tallas de santos de la Orden y ángeles, tal como la describe el P. Meléndez: "una cúpula de media naranja bellísima, adornada por dentro de Santos de la Orden hechos de media talla, de madera de cedro, que representaban una grande majestad" (24).

La cúpula se fabricó en ladrillo y fue una de las pocas que resistió el terremoto de 1746. Afirma Jorge Bernales Ballesteros que las columnas enpleadas eran de orden compuesto adosadas a gruesos pilares que abrían paso a las capillas que formaban las naves laterales (25).

Al exterior estaba divididan en secciones en las que había ventanas con frontones triangulares y una linterna también con ventanas y

(21) VARGAS UGARTE, 5. J., RuLén. Etríỹ de un diecionerio de artifices de la América meridionol. Burgos, 1968. 256-259.

(22) ANGULO, O. P., D. Concierto que rizo con el monesterio e friles del Señor Soncto Domingo, Geronimo Delgado, contero. R.A.N.P., Lima, T. XII, E. II, Jul-dic., 1939, 227. Ucos Agüero trasladaron su capiilá a la nave del ciera uno bóveda del lado del Evangelio. Los cofrades de Nuestra Señoro del

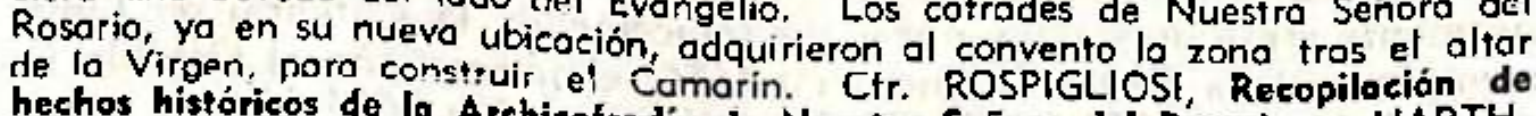
hechos históricos de la Archicolradio de Nuestro Señora del Rosario, y HARTH. (23) Se asegura muy gaiana. El Comercio, Lima, 2-VI-1948.

Xavier Domínguez desde I 68 ? roto pora reconocer los l6̊s. Después del terremoto de 1687 estuvo con Mobóveda de la capiiia daños en la Catedral de Lima. En 1685 construyó la Concierto ante Pérez del Rosario en calidad de albañil de la Cofradia. (Cfr. Archiro Menestral. Biblioteco, fs. I1 3rta. 27-I-16B5: HARTH-TERRE, Emilio. (24) MELENDE7

(25) BERNALES. '. Op. cit., T. Iil, Lib. V, Cop. IV, 810. 
pináculos que rodeaban un remate triangular que sostenía una cruz (26).

Otra de las modificaciones que derivaron de la apertura del crucero fue el cambio de lugar de la Capilla del Rosario, a consecuencia del convenio que antes se mencionó entre los descendientes de Agüero, de Aliaga y la Cofradía. En 1684 la capilla pasó a ocupar el asiento que hasta entonces ocupara la capilla de los Agüero o de Santo Cristo. Con la idea de ampliarla, la Cofradía adquirió parte del terreno situado detrás de la capilla, para destinarlo a la construcción del Camarín de la Virgen. Por cláusula estipulada en el contrato, el Cristo llamado de la Conquista debía colocarse en la parte superior del nuevo retablo de la Virgen (27). Este fue concertado con Diego de Aguirre, discípulo de Ascencio Salas, el 4 de enero de 1684.

Al trabajo del altar sumaba Aguirre, la obra del Camarín de la Virgen con su cscalera encajonada. El $1^{\text {o }}$ de febrero se comprometió a dar inicio a los trabajos, hasta por un año. Se le pagarían 11.000 pesos de a 8 reales en los que estaba incluido el valor del retablo antiguo, que fue avaluado en 2.500 pesos (28). El 18 de enero de 1687, terminados los arreglos, fue trasladada la Virgen a su nuevo lugar con la asistencia del virrey Duque de la Palata (29).

\section{EFECTOS DEL TERREMOTO DE 1687}

El 20 de octubre de 1687 un fuerte terremoto destruyó gran parte de la ciudad. El Cabildo emitió un informe con fecha 27 de abril de 1688, dando cuenta de los daños que se habían ocasionado en la ciudad, el mismo que ubicó y publicó el P. Domingo Angulo. Entre los vecinos de Lima que prestaron declaraciones, en esta ocasión se encontraba Fernández "Montaño, Cquien eralTeniente del Cabildo; Fr. Diego Maroto; Manuel de Escobar, ambos artífices, Pedro de Ascencio, Ayudante de Ingeniería Mayor. Al referirse a los daños producidos en la iglesia dominica, todos coinciden al afirmar que habían sido considerables y que la iglesia estaba muy maltratada; fue necesario apuntalarla y celebrar el Santísimo Sacramento "en el cañón principal, donde se colocó:...". Fr. Diego Maroto asegura que el movimiento había derribado la torre y que el P. Provincial Fr. Ignacio del Campo se hallaba dedicado a reparar rápidamente la iglesia. Pedro de Ascencio confirma lo dicho, añadiendo que por entonces él prestaba servicios en los trabajos. Fernández Montaño es quien describe más de-

(26) Grobodo de Meléndez: Cfr. noto No. 2.

(27) ROSPIGLIOSI, A., Op. cit.; HARTH-TERRE, E., Una capillo, cit.

(28) VARGAS UGARTE, R., Op. cit., 154-155; HART'H.TERRE, E., Escultorios espatioles en el virroineto del Perí, (Lima, 1977), 189-190. (Ánte Pérez Landero; 1684, f. 69).

(29) : FLOREZ ARAOZ, José. La iglosia de Nuestro Soffora del Rosario de Sonto Domingo. (En: Culturó Peruano, Lima, Vol. III, No. 13, oct. 1943), 31. 
talladamente los daños, dice que ". . la iglesia, las capillas, altar y demás oficinas está caido, demolido y arruinado, abiertas brechas por diferentes partes, el coro alto y bajo y sus bóvedas hundidas, y la torre caida al suelo, de donde dixo el Padre Superior Fray Manuel de Castro, habían sacado de sus ruinas quarenta y dos cuerpos muertos, y se juzgaba haber más ... porque todo lo arrasó el terremoto ... si no es en la iglesia la capilla de Nuestra Señora del Rosario, que quedó ylessa" (30).

Jorge Bernales Ballesterus informa acerca de un documento enviado al rey de España por el virrey Duque de la Palata el 6 de diciembre de 1687, a escasos días de haber ocurrido el sismo. Este dodumento presenta datos en eridente contradicción con las declaraciones cuuc posteriormente emitiría el Cabildo (31). En aquél se asegura que la iglesia no sufrió daños, sino solamente el convento.

En este trabajo se ha preferido tomar en consideración el documento de abril de 1688 emitido por el Cabildo, por considerarse que las personas consultadas tenían experiencia en materia de construcción; porque éste fue uno de los terremotos más serios que azotaron la ciudad y porque pasados algunos meses muchos daños en un principio no manifiestos pudieron determinar dichas aseveraciones. En caso de no haber sufrido mayormente la iglesia, como asegura el informe del virrey, no se justificaría el que se hubiese improvisado una capilla de madera y esteras para llevar las imágenes de la Virgen del Rosario y de Sarita Rosa a la plaza mayor, como aseveran los citados testigos. La justificación que entonces sc daba al traslado era el no haber en la iglesia lugar propicio y seguro, aparte de la capilla del Rosario, cerca del Presbiterio (32).

Observa el arquitecto Tharth-terré que-la torre entonces dañada, no fue reparada sing gmuichosiañosi después, sen la tercera década del siglo siguiente (1726) (33). No debe descuidarse el hecho de la poca documentación que existe sobre este sismo en relación a la iglesia. Entre 1687 y 1726 pudo haberse realizado una reconstrucción no documentada, pues hay que destacar que el propio Maroto y los otros testigos afirman que la torre estaba en ruinas. Algunas providencias debieron tomarse cuando tres años más tarde (1690) ante un nuevo sismo de menor intensidad que el anterior no se menciona que la haya afectado. Jos daños en esta ocasión se redujeron a ciertas partes de la iglesia, como algunos arcos que habían quedado debilitados con el

(30) ANGULO, O. P., Domingo. El terremoto del año 1687. (R.A.N.P., Lima, T. XII, E. I., ene.-jun. 1939), 345; 131-153.

(31) BERNALES BALLESTEROS, J., Op. cit., 249.

(32) ANGULO, D. El terremoto... cit.

(33) HARTH-TERRE, Emilio. La reconstrucción de la torre de Santo Domingo. (En: Arquitecto Peruano, Collao, Año IV, No. 40, nov., 1940); FLOREZ ARAOZ, J., Op. cit.; ANGULO IÑIIGUEZ, Diego. Historia del arte hispanoamericano. T. II, Cap. V, 134 (Marco Dorta, Enrique). Dice que derribaron tanto la torre como la capilla de la Veracruz, no cito documentación. 
anterior movimiento $\mathrm{y}$ no habian sido convenientemente reparados (34).

\section{ORNAMENTACION INTERIOR DURANTE EL SIGLO XVII}

Varias adquisiciones hizo el conyento dominico para la iglesia entre 1625 y 1627 . El provincial Fr. Salvador Ramírez encargó tres imágenes para el templo: un Santo Tomás, un Santo Domingo y un Santo Cristo llamado "de Aliaga" que era propiedad de los descendientes de Juan de Aliaga, según informa el P. Meléndez (35).

Por su parte la Cofradía de la Virgen del Rosario decidió decorar su capilla con azulejos. E.n 1643 encargó a Juan del Corral que fabricase "un suelo de losas finas matizado con azulejos y un laso y medio". El convenio se firmó ante Nicolás García (36).

En 1651, Fugrenio Dias suscribió un contrato, esta vez con el convento, ante iMigııl López Varela, por el cual debía fabricar azulejos para el Coro Alto de la iglesia, de "ladrillo colado y entreverado con azulejos estrellados del tamaño y modo que tienen comunicado [entré ambas partes] con lazo y medio al modo y tamaño que está en la Capilla Real de la Corte". Anadía que "asimismo se obligaba a solar el antecoro con el ladrillo que saliera del Coro y según y de la forma que el dicho Coro está hoy en sus cuadritos de azulejos (37). Estos azulejos cubrieron los pisos de ambas secciones, pero posteriormente fueron retirados.

La Cofradía del Rosario emprendió nuevas reformas y arreglos en su capilla durante lós años siguientes. En 1651 de fueron encargados al pintor Tomás Ortiz los óleos de La Visitación, La circunsición y La Revelación. Fn mavo gel añoisiguiente se doró y añadió piezas al retablo de la Virgen, obra que fue encargada al dorador y ensaniblador José del Aguila, a quien se pagó 1.300 pesos por su trabajo (38).

(34) ANGULO; O. P., Domingo. El terremoto de 1690. (R.A.N.P., Limo, T. XIII, E. I., ene.-jun,, 1940), 6.

(35) MEL.ENDEZ; J., Op. cịt., T. III, Lib. I, 128 y 136. EI P. Meléndez asegura que dichas obros le fuerón encorgadas a Juan Martínez Montoñés. En un estudio sobre el escultor sevillono publicado en 1967 por Beatrice Gilman PROSKE (Juon Martínez Montoñés sevillian sculptor. New York, 1967), ésto hace referencio a los esculturas de Santo Domingo y de Santo Tomás señalando que oún no han sido identificados, a pesar de las sugerencias del $P$. Vargas Ugarte (Op. cit., 109 y 181 ). Debe señalarse ademós que el periodo provincial del $P$. Ramirez fue del 2-X-1625 al 2-XI1-1627, no anterior como lo señala Proske. (Cfr. AREVALO, O. P. José Marío. Lós dominicos en el Perú. (Visión histórica). Limna, $1970 ;, 162 . \cdots, j$,

(36) HARTH-TERRE, Emilio. El azulejo eriollo en la arquitectura limeña. En: R.A.N.P., Limo, T. XXI1, E.. II, 1958, 414: (Ante Nicolós Gorcía, f. 147. 1643. ANP., 417, (tronscripción).

(37) Ibidem.' 417. (Ante Miǵuel López de Vorela, fol. 73, 1651, ANP). (38) VARGAS UGARTE, R,; Op. cit., 152. (Airch.' Arz. Limo, Sécc. Cofradías). 
Eu 1653 se encargó nuevamente a Juan del Corral unos azulejos para cubrir la capilla del Rosario. El P. Alonso Prieto acordó pagarle tres reales por cada losa fina y veintidós reales por cada ciento de azulejos, pero al año siguiente se rescindió el contrato, frustrándose el proyecto (39).

La capilla del Rosario de los Pardos fue redecorada a su vez. En 1666 Diego de Aguilera cubrió las paredes y la bóveda de la capilla de acuerdo al contrato que concertó el 7 de abril de ese año con el capitán Francisco Vásquez que era dorador (40).

En 1670 Pedto Cornejo colocó unos azulejos en la iglesia, presu* miłhlemente hechos en una fábrica que tenían los franciscanos, aunque el $\mathrm{P}$. Gento asegura en su San Francisco de Lima, que nunca existió tal fábrica (41). Ese mismo año Fr. Cristóbal Caballero se dedizó a dorar las tallas de la iglesia, completando un trabajo que había iniciado en la capilla de los Pardos en 1661 (42).

El 15 de julio de 1670, llegó al Callao una escultura yacente en mármol de Carrara de Santa Rosa de Lima. Esta obra había sido encargada en 1668 al escultor Melchor Caffa por el Pontífice Clemente IX para obsequiarla a la Orden de los Predicadores de Lima. Cinco días después la escultura fue llevada en hombros hasta Lima. Dentro del estilo barroco italiano de Bernini, dicha obra constituyó desde entonces uno de los mayores atractivos de la iglesia dominica y está considerada entre las mejores realizadas por su autor. Actualmente se encuentra en el altar de la Santa, el primero del lado del Evangelio (43).

E) 4 de enero de 1684 ese encomendó a Diego de Aguirre un nuevo retablo para adornar la capilla de la Virgen del Rosario. El contrato se firmó anter fos Mayordomos de la Cofradía, Lucas Alagueros y Manuel Fernández Dávila, quienes tenían poder de los Hermanos 24. Tue concertado en 11 mil pesos. Estos, habiendo reconocido las trazas y proyectos que se presentaron para la obra del retablo, "que se ha de poner en la capilla que hoy está en la de Santa Rosa al lado dei Evangelio", aceptaron el proyecto presentado por Aguirre "porque además de haver hecho otros retablos buenos, es persona competente para hacer las enmiendas que conviene". El retablo se basaba en un diseño de Aguirre, en cedro, exceptuando los fustes de las columnas que scrían en roble tallado y el trono donde iría la imagen lo haría "de la misma forma que el modelo que se envió a Venecia para traer las columnas y demás cosas de cristal" que el maestro colocaría,

(39) HARTH-TERRE, Emilio. Aftifices en el virreinato del Perú. Lima, $1945,170$.

s. $p$.

(40) VARGAS UGARTE, R., Op. cit., 152; FLOREZ ARAOZ, J., Op. cit.

(41) GENTO SANZ, B., Op, cit., 281.

(43) FLOREZ ARAO, E., Anifices... cit., 193.

(43) FLOREZ ARAÓZ, J., Op. cit., s.p. 
dándole la Cofradía además de estas piezas, los bronces, fierros y plata indispensables para fijarlas en su sitio (44).

Hacia tines del siglo XVII se encargó al escultor Francisco Mar-tínez una escultura de Jesís Nazareno destinada a la capilla del mismo nombre situada en la nave del Evangelio. El contrato lo suscribió Dn. Sebastián Mesía a nombre de la Cofradía (45).

La historia constructiva de la iglesia de Nuestra. Señora del Rosario de Santo Domingo está estrechamente vinculada a los terremotos que asolaron Lima. Durante è siglo XVI, en 1586 un sismo dio lugar a la terminación de la segunda iglesia y definitiva. El siglo XVII soportó un fuerte terremoto en 1678, cuyos estragos propiciaron la intervención del arquitecto criollo Fr. Diego Maroto O.P. Al construir una cúpula sobre el crucero, amplió la capilla mayor, variando sustancialmente la configuración que tenía el templo hasta entonces. Esta modificación no afectó la téchumbre de lacería, la que debió desaparecer, al igual que las pinturas de Mateo Pérez de Alesio én la misma zona, en el terremoto de 1687. Durante este sismo cayó igualmente la torre diseñada por Fr. Diego Maroto en 1657. Sus cimientos fueron empleados al siğlo sigúiente para construir la que observamos hoy.

En cuanto a la ornamentación de la iglesia, los azulejos fueron utilizados con profušión para realzar los muros. y pisos de sus diferentes secciones. Así mismo désde España e Italia, llegaron esculturas de renombrados artistas, las que fueron colocadas en los retablos de las capillas del templo.

Debe destacarse' la partiçipación cada vez más contínua de artífices criollos y mestizos en los trabajos de edificación y ornamentación realizados en la época.

\section{"Jorge Puccinelli Converso"}

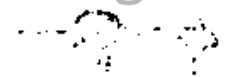

(44) HARTH-TERRE, E., Eseultores ... eit., 189-190. (Gamboa, controto ante Pedro Pérez Landeró, fs. 273 y vto. 22-Xil-i 685, Archivo Menestral). VARGAS UGARTE, R., Op. cit., 194-195.

(45) HARTH-TERRE, E., Uno copilla muy. . . cit. 


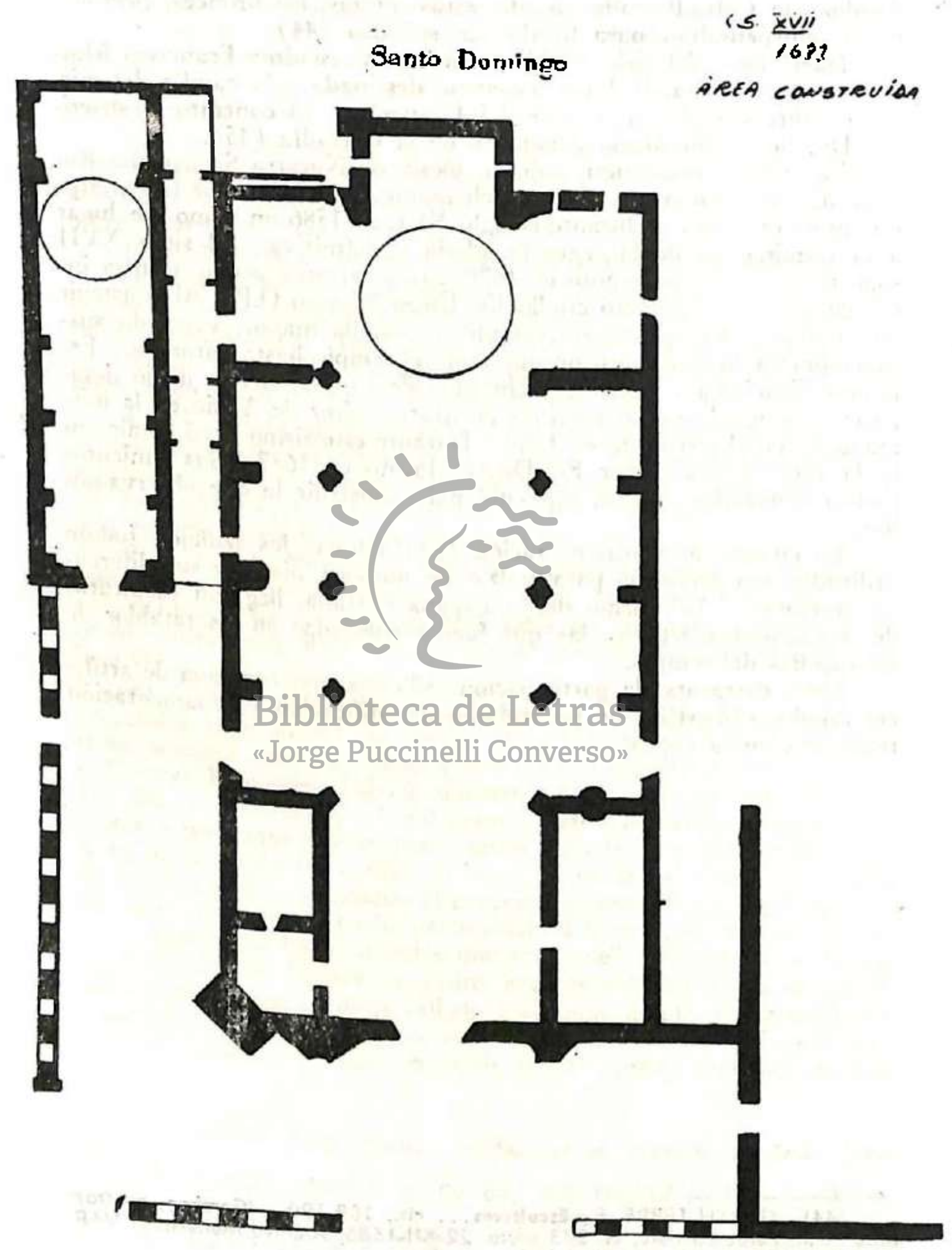

